\title{
Determination of Genetic Distance among Genotypes of Cucumber, Cucumis sativus L., Using ISSR Marks
}

\author{
Idrees H. M. AL-Jaf, Khudhaier A. A. AL-Jubouri \\ Horticulture Dept., College of Agriculture - University of Baghdad, Iraq
}

\begin{abstract}
This research was conducted in biotechnology laboratories of grain test and validation office Ministry of Agriculture, 2016. Nine cucumber genotypes, represented pure local and imported classes,were cultivated to evaluate genetic diversity and determine genetic affinity among them by using 13 starters kind Inter Simple Sequence Repeats (ISSR), 10 of them showed an activity to give apolymorphism among the studied genotypes which give 94 alleles, the ratio of this polymorphism was 68\%. The starter UBC862 gave higher bands of 15, while the starter A35 gave lower bands of 6. The study showed that genetic similarity of the genetic affinity ranged between 0.506 - 0769 in which the higher genetic affinity (0.769) was for V5 and V2 varieties followed by (0.743) for V6 and V3 varieties, while the lower genetic affinity (0.506) was for V8 and V9 varieties. Keywords: Cucumber, polymorphism, ISSR, allele.
\end{abstract}

\section{Introduction}

Genetic diversity within plant varieties is an important part of biodiversity. Plant genetic sources characterized by the large genetic diversity and its ability to tolerate biogenic and non-biogenic stresses [3]. Genetic diversity contributed to provide human needs of food, clothing, medicine and energy, and even exceeded to the environmental importance, prompting plant breeders to adopt genetic diversity indicators as a source of genetic information about the crops to be used in the indirect selection of the properties associated with these indicators [1].

Cucurbitaceae including about 90 genus and more than 750 species . Cucumber (Cucumis sativus L.) is most important of those species as its fruits, in tropical regions, are a source of carbohydrates despite the low ratios [22]. Cucumber is one of important and desirable economic crops in Iraq as its fruits are used as aperitif, consumed freshly or with salad or pickles. Cucumber fruits containing of 0.9 protein, 0.1 fat, 3.4 carbohydrates, 0.3 mineral material, and a little of vitamins [4]. Cucumber is di-chromosomes $(2 \mathrm{n}=14)$ and most of its genus considered as monoecious. Although the flowers formed completely, one of its sexual organs developed atrophying the other organ, then the flower is either male or female. Cucumber is one of partially mixed inoculation with high proportion [5].

The methods of plant varieties characterization and classification, depending on their morphological and production properties, are the earliest, but mostly affected by dominant environmental conditionsgiving similar results difficult to be adopted for recognizing the differences as well as they need great time and effort [30]. These methods must be promoted by modern biotechnologyto characterize the genetic sources using molecular indicators that have many numbers, stable results, and unaffected by environmental conditions [18].

Currently, biotechnology is one of assistance means improving crop and food production and this technique became known in the practical stages in many developed countries. The use of biotechnology at the molecular level of the genetic material DNA led to accelerate the improvement of crops, as it helps selecting and breeding thereby reducing the time of the classic breeding [16]. Genetic material can be extracted from RNA at the early stages of the plant, and easily identifying specific gene that directly responsible for the trait, and the molecular study not affected by plant morphology and environmental factors as in the case of conventional breeding programs.

[17] explained that the use of molecular techniques can reduce the complexities of inserting a number of desirable traits into the genotype. Also, molecular indicators can be used effectively in the analysis of genetic diversity and evaluating the genetic similarity. Inter Simple Sequence Repeat (ISSR) is one of the important techniques that depends on Polymerase Chain Reaction (PCR) which applied by [32]. [14, 23, 19] found the importance of using molecular DNA indicators in improving the quality and productivity of cucumber. $[21,7$, $10,25]$ confirm the importance of molecular DNA indicators in forming genetic link maps of cucumber. [24] identifiedthe sites of genes, that responsible of parthenocarpy in cucumber, by using molecular DNA indicators. ISSR was used to study the genetic diversity in cucumber and watermelon [27]. [20, 19, 11,9] indicated to the importance of using morphological and molecular indicators in improving cucumber quality and productivity. Seven genetic link groups were determined using morphological, molecular and enzyme indicators adopting AFLP technique by $[7,31]$, the molecular indicators gave more than 300 gene sites which greatly contributed in 
determining the link groups. This research aimed to the genetic characterization of some cultivated cucumber varieties and determining the genetic affinity among them using ISSR technique.

\section{Methods and Materials}

Plant material consisted of nine genotypes of Cucumis sativus L. collected from different locations. The research was conducted in the biotechnology laboratories of the Grain Test and Validation Office Ministry of Agriculture. Grains of the nine cucumber genotypes were planted,to sustain their grains and increase their genetic originality, in the Center of Research fields. Genotypes grains, resulted from the previous season, were planted into filled peat moss pots and placed in the greenhouse and the samples were taken at the appearance of actual leaves to be used in DNA isolation.

\section{Genome DNA Isolation}

DNA was isolated from the young studied genotypes leaves and DNA quantity, about $50-150 \mathrm{Mg}$ per $1.5 \mathrm{~g}$ leaves for each cucumber genotype with a purity ranged between $1.7-2$ which measured by Nanodrop device. DNA samples dilutions were fitted to obtain $50 \mathrm{ng}$. $\mathrm{ML}^{-1}$ concentration that appropriate for PCR. There are many methods to isolate nucleic acids from the plants due to the plant diversity contains different quantities of plant compounds such as proteins,polysaccharides and nucleic acids. ISSR Marks, that depending on PCR and 13 starter, was used (Table 1). The method of [28] was adopted to isolate DNA from cucumber which had an efficiency to isolate the DNA [6]. Relatively, DNA isolation from the plant is more difficult than other organisms due to the presence of the thick wall surrounding the cell membrane as well as some plants contain large amounts of phenol materials and polysaccharides which considered as pollutants that sometimes deposit with the DNA giving a high viscosity liquid as well as considered as inhibitor for PCR. To get rid of these materials, a dilution of the extracted DNA was conducted to reduce the ratio of saccharide inhibitors.

\section{ISSR Application}

In this study, 11 starters were used after importing from Bloneer Co. Table 1 showed the Nucleotide Sequence and the coalescence temperature of the starters used in the study.

Table 1: Nucleotide Sequenceof the starters used in ISSR

\begin{tabular}{|c|c|c|}
\hline Starter & Nucleotide Sequence 3-5 & Temperature \\
\hline UBC480 & GAGAGAGAGAGAGAGAYT & 33.7 \\
\hline UBC842 & GAGAGAGAGAGAGAGAYG & 36.3 \\
\hline UBC858 & TGTGTGTGTGTGTGTGRT & 42.4 \\
\hline UBC807 & AGAGAGAGAGAGAGAG T & 29.9 \\
\hline UBC862 & AGCAGCAGCAGCAGCAGC & 57.5 \\
\hline A35 & AGAGAGAGAGAGAGAGCT & 40 \\
\hline N35 & GAGACC & 20 \\
\hline A34 & GCGCGTGTGTGTGTGT & 36.9 \\
\hline 813 & CTCTCTCTCTCTCTCT T & 32.2 \\
\hline UBC815 & CTCTCTCTCTCTCTCTG & 40 \\
\hline 834 & AGAGAGAGAGAGAGAGCTT & 41.9 \\
\hline UBC860 & TGTGTGTGTGTGTGTGRA & 28.4 \\
\hline UBC879 & CTCTACTTCACTTCA & \\
\hline
\end{tabular}

PCR was conducted according to [29] with some modifications andthe final reaction volume was $25 \mathrm{ul}$ using $2 \mathrm{x}$ Master mix obtained from Bloneer Co. The reaction consisted from $2 \mathrm{ul}$ of the starter with concentration of $10 \mathrm{~m}$ M, 12.5ul of Master mix, 9ul of distilled water, and DNA with concentration of $40 \mathrm{ng}^{-\mathrm{ul}^{-1}}$. This reaction occurred into thermo-rotation system according the following conditions:

1- Separation: at $94^{\circ} \mathrm{C}$ for 5 minutes, the two series of DNA to be separated.

2- 40 rotations, each includes the following stages:

2-1 Separation occurred at $94^{\circ} \mathrm{C}$ for $30 \mathrm{sec}$.

2-2 Coalescence: according to the temperature of each starter, from table 1 , for 1 minute.

2-3 Elongation at $72^{\circ} \mathrm{C}$ for 1 minute.

3- Reaction completion at $72^{\circ} \mathrm{C}$ for 1 minute.

The samples were kept under $4^{\circ} \mathrm{C}$, thendeported on Acaruz gel.

The Electric Deportation, Coloring and Imaging

The deportation on Acaruz gel (2\%) was done into the buffer solution TBE 1x.

TBE 1x = (10x TBE buffer $=108 \mathrm{~g}$ Tris borate $+55 \mathrm{~g}$ Boric acid + 9.2 EDTA, ph 0.8)

$5 \mathrm{ul}$ of ethidium bromide stain $\left(10 \mathrm{mg} \cdot \mathrm{ml}^{-1}\right)$ where DNA samples were loaded on Acaruz gel by adding $5 \mathrm{ul}$ of the special loading liquid (Bromophenol bluw 1x loading buffer).1kpb DNA, from Geneaid Co., was injected to determine the volume and molecular weight of the resulted bands, then deporting by passing through electric 
field of $100 \mathrm{v}$ to separate DNA bands resulted from the amplification, then imaging the gel by the image analyzer (Eagle Eye II Stratagene).

\section{Statistical Analysis}

The results of the amplification process gathered in a table depending on the presence or absence of DNA bands in the studied samples, the number 1 indicates to the presence of clear DNA band only, while the number 0 indicates absence of the band. Individually the tables were organized for each starter and the dendrogram was drawn by applying Unweighted Pair Group Method with Arithmetic Averaging (UPGMA) using the Statistical Past.

\section{Polymorphism}

[13] used starters, 10 of them, had an ability to detect the genetic differences among different pure varieties. Table 2 showed that used starters gave 94 bands, 68 of them had a polymorphism with ratio of $72 \%$. That indicated to the genetic distance among the pure cucumber varieties used in the study. The table showed that the starter UBC862 gave greater band number (15 bands) compared to the other used starters, while the starter A35 showed least bands number (4 bands) through sample deportation on poly acryl amide gel.This variation in the number of bands, resulted from each pair of used starters, depends on the correspondence extent of the starter link with plant genome as well as the components of each starter of nitrogenous bases. The sequence difference of used starters bases led to the difference of their link sites with the plant genome and this led to difference in bands number resulted from the used starters [26]. In spite of the difference in the bands number, the starters succeeded to give polymorphism among the resulted bands which reached $100 \%$ in the starters UBC842, UBC858, and A35, while the starter A34 had no more than $25 \%$ of polymorphism. This variation in the percentages attributed to the difference in the sequence of bases in the plant genome which affected the starters link sites, and this difference was caused by genetic rearrangement, link, passing and other. Different bands appeared clearly on the gel or do not appear in certain sites on the gel [2].

Table 2: Number of bands and polymorphism of the used starters

\begin{tabular}{|c|c|c|c|}
\hline Starters & Bands number & Polymorphism\% & Polymorphism \\
\hline UBC480 & 6 & 83 & 5 \\
\hline UBC842 & 8 & 100 & 8 \\
\hline UBC858 & 8 & 100 & 8 \\
\hline UBC807 & 11 & 63.6 & 7 \\
\hline UBC862 & 15 & 46.6 & 7 \\
\hline $\mathbf{A 3 5}$ & 4 & 100 & 4 \\
\hline $\mathbf{N 3 5}$ & 7 & 85.7 & 6 \\
\hline A34 & 12 & 25 & 3 \\
\hline 813 & 11 & 81.8 & 9 \\
\hline UBC815 & 12 & 91.6 & 11 \\
\hline Total & 94 & & 68 \\
\hline Average & & $\% 72$ & \\
\hline
\end{tabular}

\section{Determination of Genetic Affinity among Studied Genotypes}

Genetic distance, among studied genotypes, was calculated according to the equation of [15]. The result showed the similarity and dissimilarity extent among the pure ancestries. The higher similarity percentage, which corresponded to less genetic distance (0.769), was between V5 and V2 followed by V6 and V3 which formed a small group, while less similarity percentage, which corresponded to great genetic distance (0.506), was between V9 and V8 followed by V8 and V2 genotypes. According to the results, showed in the table 3, it can be observed that V9 and V8 genotypes had greater genetic distance than others.

Table 3: Values of the genetic similarity among 9 cucumber genotypes

\begin{tabular}{|c|c|c|c|c|c|c|c|c|c|}
\hline & $1 \mathrm{~V}$ & $2 \mathrm{~V}$ & $3 \mathrm{~V}$ & $4 V$ & $5 \mathrm{~V}$ & $6 \mathrm{~V}$ & $7 \mathrm{~V}$ & $8 \mathrm{~V}$ & $9 \mathrm{~V}$ \\
\hline $1 \mathrm{~V}$ & 1 & & & & & & & & \\
\hline $2 V$ & 0.666 & 1 & & & & & & & \\
\hline $3 \mathrm{~V}$ & 0.538 & 0.535 & 1 & & & & & & \\
\hline $4 \mathrm{~V}$ & 0.656 & 0578 & 0.708 & 1 & & & & & \\
\hline $5 \mathrm{~V}$ & 0.709 & 0.769 & 0.585 & 0.635 & 1 & & & & \\
\hline $6 \mathrm{~V}$ & 0.555 & 0.493 & 0.743 & 0.693 & 0.564 & 1 & & & \\
\hline $7 \mathrm{~V}$ & 0.683 & 0.549 & 0.524 & 0.657 & 0.632 & 0.602 & 1 & & \\
\hline $8 \mathrm{~V}$ & 0.513 & 0.512 & 0.662 & 0.631 & 0.608 & 0.623 & 0.540 & 1 & \\
\hline $9 \mathrm{~V}$ & 0.694 & 0.557 & 0.569 & 0.642 & 0.617 & 0.567 & 0.666 & 0.506 & 1 \\
\hline
\end{tabular}




\section{Cluster Analysis}

Cluster analysis allowed to divide the studied genetic structures into groups reflecting the genetic affinity among them according to their originality. The dendrogram, depended on values of the genetic distanceusing UPGMA method (Fig 1) which created according to the results of ISSR indicators, showed that the 9 genotypes distributed into two main groups, A and B. The cluster A included 4 genetic structures (V8, V4, V6, and V3) and it can be observed in the group A that V3 and V6 genotypes had a distance between each other of 10, between V6 and V4 of 9, and between V4 and V8 of 8. The cluster B divided into two main branches: the first branch included V5 and V2, and the second included V1, V9, and V7. The V7 and V9 had a distance between each other of 8 , and between V9 and V1 of 10, while between V5 and V2 of 10.It can be concluded that molecular study showed the studied cucumber genotypes contained high genetic variety and these results can be used as an essential material in the programs of breeding by hybridizing to improve the quantity and quality properties and produce cucumber individual hybrids. The results found to be similar to $[12,13]$

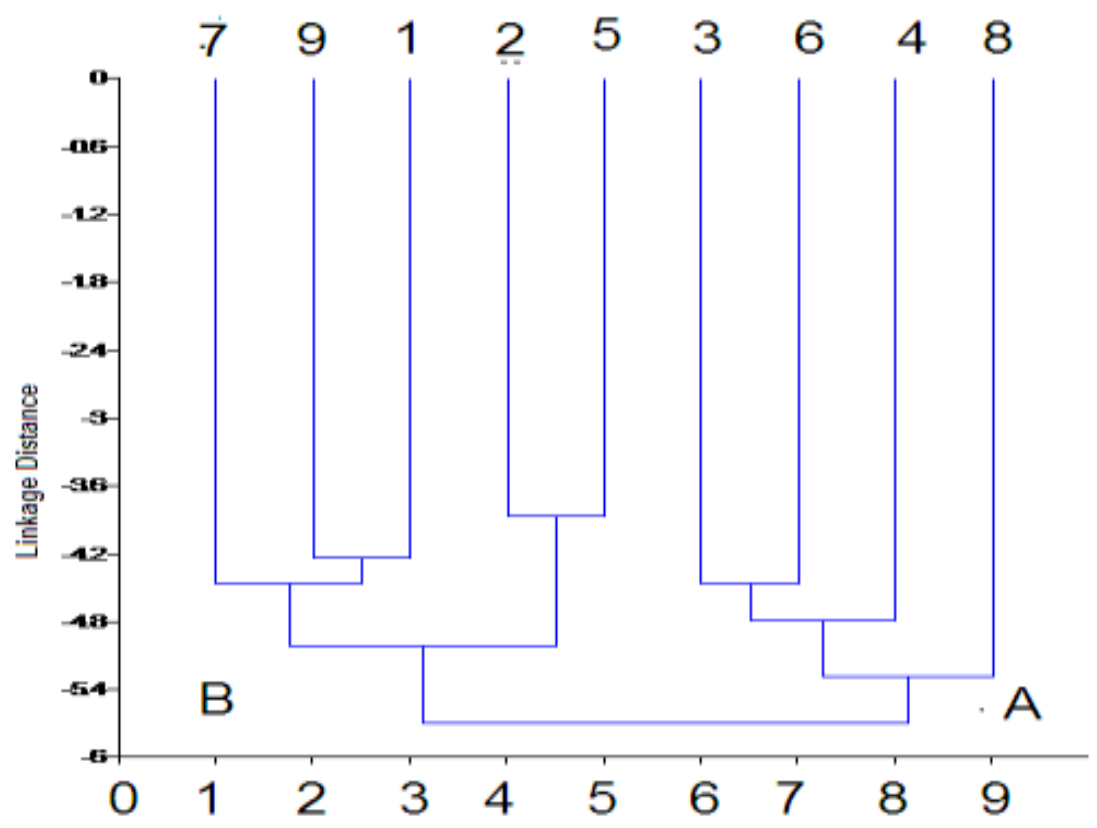

Fig 1: Dendrogram of the Studied Genotypes

\section{References}

[1]. Alfalahi, A. O. 2011. Phenotyping and Molecular Variations of Maize CMS Population and Subpopulations. Ph.D. Thesis, Dept. of Field Crop, Coll. of Agric., Univ. of Baghdad. pp. 98.

[2]. Bradeen, J.M., J.E. Staub, C. Wyse, R. Antonise, and J.Peleman,. 2001. Towards an expanded and Integrated linkage map of cucumber (Cucumis sativus L.). Genome .44: 111-119.

[3]. Eleuch, L., A. Jalil, S. Grando, S. Ceccarelli, M.K. Schmising, H. Tsujimoto, A. Hajer, A. Daaloul. and M. Baum. 2008. Genetic diversity and association analysis for salinity tolerance, heading date and plant height of barley germoplasm using simple sequence repeat markers. J. Integ. Plant Biolo. 50(8):1005-1015.

[4]. Fan, Z., M .Robbins, and J. Staub,. 2006. Population development by phenotypic selection with subsequent marker-assisted selection for line extraction in cucumber ( Cucumis sativus L.). Theor Appl Genet 112: 843-855.

[5]. Fazio, G, S.M. Chung and J.E. Staub, 2003b, Comparative analysis of response to phenotypic and marker-assisted selection for multiple lateral branching in cucumber(Cucumis sativus L.). Theor. Appl. Genet. 107: 875-883.

[6]. Fazio, G., J.E. Staub, and M.R. Stevens, 2003a, Genetic mapping and QTL analysis of horticultural traits in cucumber (Cucumis sativus L.) using recombinant cucumber (Cucumis sativus L.) using recombinant inbred lines. Theor. Appl. Genet. 107: 864 - 874.

[7]. Ferriol,M., B. Pico and F.Nuez, .2004b.Morphological and molecular diversity of a collection of Cucurbita maxima landraces.J.Amer.Soc.Hort.Sci.,38,1688-1696

[8]. Ferriol,M., B.Pico, P. Fernandez and F.Nuez, .2004 a. Molecular diversity of a germplasm collection of Squash (Cucurbita moschata)determined by SRAP and AFLP Markers. Crop Sci :,44,653-664.

[9]. Haherla. Mokhlas, and Khaled Opry and Ghassan and Bassam Nabulsi Molloy. 1995. priorities of the Wildlife Conservation of genetic resources in Syria, Damascus, Syria.

[10]. Hamdallah, Majid Shaya. 2009. The role of molecular genetic technologies to draw the maps and estimate the genetic divergence genetic footprint. Iraqi Journal of Agricultural Sciences 0.40 (3): 50-62.

[11]. Horejsi, T., J.M. Box and J.E. Staub. 1999. Efficiency of randomly amplified polymorphic DNA to sequence characterized amplified region marker conversion and their comparative polymerase chain reaction sensitivity in cucumber. J. Am. Soc. Hort.

[12]. Khairallah, Hossam Saad Eddin Mohammed 0.2007. Micropropagation of two types of date palm Phoenix dactylifera L.)) using the inflorescence and floral study the genetic stability using Amplified Fragment Length Polymorphism imarkers (AFLP), a doctoral thesis. Horticulture section. Baghdad University . lraq 
[13]. Mohammed, Izz al-Din Sultan 0.1983. The production of vegetable seeds. Ministry of Higher Education and Research, the Republic of Iraq.

[14]. Nei, M. and W.H. Lei, 1979. Mathematical model for studying genetic variation in terms of restriction endonucleases. Proc. Natl. Acad. Sci. USA., 76: 5269- 5273.

[15]. Powell,W., M. Morgante, C.Andre, M.Hanafey ,J.Vogel, S.Tingey and A.Rafalski,.1996. The comparison of RFLP, RAPD, AFLP and SSR (microsatellite) markers for germplasm analysis .Mol.Breed. 2, 225-238.

[16]. Qubaisi, Hassan.2007. Lexicon herbals and medicinal plants, Dar of scientific books Beirut. The seventh edition, p 245-251.

[17]. Ramsay, L., M. Macaulay. S. Degli Ivanissevich. K. Macleanm. L. Carsle.; J. Fuller, et al. 2000. A simple sequence repeat-based linkage map of barley. Genetics, 156:1997-2000.

[18]. Ricciardi, L., V.Giorgio. C. De Giovanni. C. Lotti. A. Gallotta and G. Fanizza. 2002). The genetic of apulian apricot genotypes (Prunus armeniaca L.) assessed using AFLP markers. Cellular and Molecular Biology Letters. 7:431-436.

[19]. Robbins, M. D., 2006, Molecular marker development, QTL pyramiding, and comparative analysis of phenotypic and markerassisted selection in cucumber. PhD dissertation University of Wisconsin, Madison.

[20]. Robbins, M. D.and J.E. Staub,. 2004 .Strategies for selection of multiple quantitatively inherited yield component in cucumber . Eucaepia Conference Progress in cucurbit genetics and breeding research . Olomouc,Czech Republic. P.401-410.

[21]. Serquen, F.C., J. Bacher, and J.E. Staub, .1997. Mapping and QTL analysis of a narrow cross in cucumber(Cucumis sativus L.) using random amplifiedpolymorphic DNA markers. Mol.Breeding3: 257-268.

[22]. Sitterly, W.R. 1972. Breeding for disease resistance in cucurbits. Ann. . Phytopathol. 10:479.

[23]. Staub , J.E., M.D. Robbins, S.M.Chang, and Z. Sun . 2006. History and application of molecular markers for cucurmber improvement .Cucurbitaceae p:197-205.

[24]. Staub, J.E., M.D. Robbins, and A. I. López-Sesé,. 2002,. Molecular methodologies for improved genetic diversity assessment in cucumber and melon. In: J. D. Creight, ed., Proceedings XXVI IRC,. Horticulture: Art and science for life- Advances in vegetable Breeding. Acta Horticulturae 642:41-47.

[25]. Sun Z., R.L. Lower, S.M. Chung, and J.E. Staub,. 2006. Identification and comparative analysis of quantitative trait loci (QTL) associated with parthenocarpy in processing cucumber. Plant Breed.125:281-287.

[26]. Vos P., R. Hogers, M. Bleeker, ,M. Reijians, , T.van de Lee, M.Hornes, A.Frijters, , J. Pot, J. Peleman, M.Kuiper,and M.Zabeau,. 1995. AFLP: a new technique for DNA fingerprinting. NucleicAcids Research;23(21):4407- 4414.

[27]. Watcharawongpaiboon,N.,andJ.Chunwongse,.2008.Develop-ment and characterization of microsatellite markers from an enriched genomic library of cucumber(Cucumis sativus).Plant Breeding .127:74-81.

[28]. Weigand, F., M. Baum and S. Udupa, 1993. DNA molecular marker techniques, technical manual. No.20.International Center for Agricultural Research in the Dry Area (ICARDA).Aleppo, Syria pp:135.

[29]. Williams, J. G. K., A. R. Kubelik, K. J. Livak. J.A. Rafalski and S.V. Tingey. 1990. DNA polymorphisms amplified by arbitrary primers are useful as genetic markers. Nucleic Acids Research 18(22): 6531-6535.

[30]. Wjhani, Y. 2004. Genetic studies on the biodiversity of local and wild Syrian wheat using modern biotechnological techniques. Thesis submitted in partial fulfillment for the requirements of the degree of doctor of philosophy in agriculture science (genetics), Department of genetics, Cairo Univ., Fac. Agric., 119 p.

[31]. Yuan XJ.., X.Z. Li, J.S. Pan, G. Wang,and S. Jiang,. 2008. Genetic linkage map construction and location of QTLs for fruitrelated traits in cucumber. Plant Breeding 127: 180-188.

[32]. Ziekiewicz, E., A. Rafalski and A. Labuda. 1994. Genome fingerprinting by simple sequence repeat (SSR) anchored polymerase chain reaction amplification. Genomics 20:178-183. 